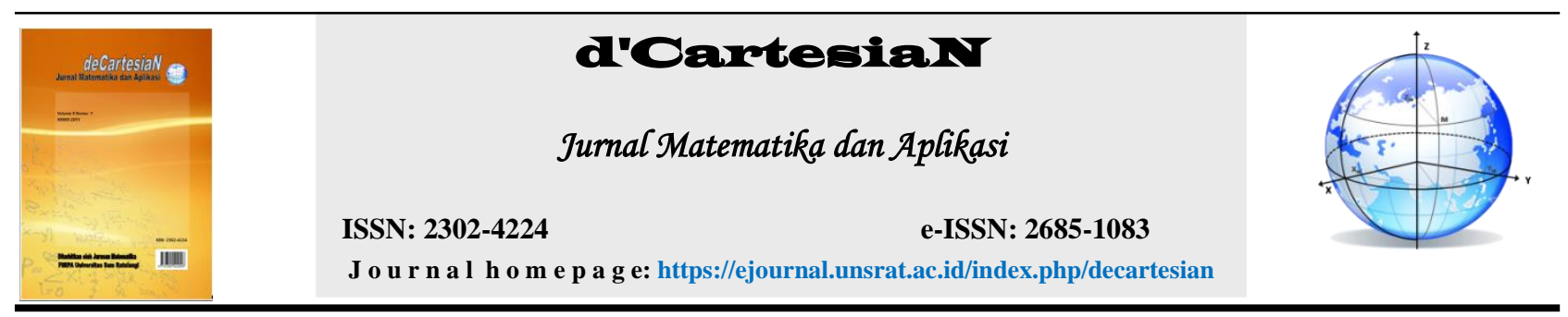

\title{
Pengelompokkan Kecamatan Berdasarkan Potensi Pertanian di Kabupaten Halmahera Selatan dengan Analisis Gerombol
}

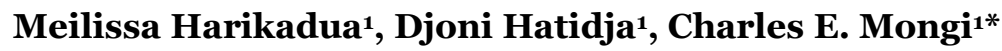 \\ ${ }^{1} J u r u s a n$ Matematika-Fakultas Matematika dan Ilmu Pengetahuan Alam-Universitas Sam Ratulangi Manado,Indonesia
}

${ }^{*}$ Corressponding author : charlesmongi@unsrat.ac.id

\section{A B S T R A K}

Penelitian ini bertujuan untuk mengelompokkan kecamatan-kecamatan berdasarkan potensi komoditi-komoditi pertanian, perkebunan, peternakan, perikanan laut dan kehutanan di wilayah Kabupaten Halmahera Selatan. Data yang digunakan dalam penelitian ini adalah data sekunder yang di ambil dari website Badan Pusat Statistik Kabupaten Halmahera Selatan.

Analisis yang digunakan dalam penelitian ini adalah Analisis Gerombol (Cluster) dengan metode single linkage dan hasil yang di peroleh adalah terbentuknya 3 kelompok di antaranya Kelompok 1 terdiri dari 28 kecamatan yaitu: Obi Selatan, Obi, Obi Barat, Obi Timur, Obi Utara, Bacan, Mandioli Selatan, Mandioli Utara, Kepulauan Batang Lomang, Bacan Timur Selatan, Bacan Timur Tengah, Bacan Barat, Kasiruta Barat, Kasiruta Timur, Bacan Barat Utara, Kayoa, Kayoa Barat, Kayoa Selatan, Kayoa Utara, Pulau Makian, Makian Barat, Gane Barat, Gane Barat Selatan, Gane Barat Utara, Kepulauan Joronga, Gane Timur, Gane Timur Tengah dan Gane Timur Selatan. Kelompok 2 hanya terdiri dari kecamatan Bacan Selatan dan Kelompok 3 yang juga hanya terdiri dari kecamatan Bacan Timur.

\section{INFO ARTIKEL}

Diterima : 13 Oktober 2019

Diterima setelah revisi : 23 Oktober 2019

Tersedia online : 28 Oktober 2019

\section{Kata Kunci:}

Analisis Gerombol

Kabupaten Halmahera Selatan

Single Linkage

\begin{abstract}
A B S T RA C T
This study aims to classify sub-districts based on the potential of agricultural, plantation, livestock, marine fisheries and forestry commodities in the area of South Halmahera Regency. The data used in this study are secondary data taken from the website of the Central Statistics Agency of South Halmahera Regency.

The analysis used in this study is Cluster Analysis with a single linkage method and the results obtained are the formation of 3 cluster including Cluster 1 consisting of 28 districts namely: South Obi, Obi, West Obi, East Obi, North Obi, Bacan , South Mandioli, North Mandioli, Batang Lomang Islands, South East Bacan, Middle East Bacan, West Bacan, West Kasiruta, East Kasiruta, North West Bacan, Kayoa, West Kayoa, South Kayoa, North Kayoa, Makian Island, Makian Barat, Gane West, South West Gane, North West Gane, Joronga Islands, East Gane, Middle East Gane and South East Gane. Cluster 2 consisted of South Bacan sub-district and Cluster 3 consisted of East Bacan sub-district.
\end{abstract}

\section{ARTICLE INFO}

Accepted : 13 October 2019

Accepted after revision : 23 October 2019

Available online : 28 October 2019

\section{Keywords:}

Cluster Analysis

South Halmahera Regency

Single Linkage

\section{PENDAHULUAN}

Secara umum pertanian adalah suatu kegiatan manusia yang termasuk didalamnya yaitu bercocok tanam, beternak, perikanan dan juga kehutanan. Hasilhasil pertanian yang umum di Indonesia diantaranya sayuran, buahan, hewan ternak, perikanan laut, dan hasil-hasil kehutanan [1].

Kabupaten Halmahera Selatan merupakan salah satu kabupaten di Indonesia yang memiliki 30 kecamatan dimana kecamatan-kecamatannya tersebar dalam sejumlah pulau, baik pulau-pulau besar maupun 
kecil, maka penelitian ini bertujuan untuk mengelompokkan kecamatan-kecamatan yang ada berdasarkan potensi komoditi-komoditi pertanian, perkebunan, peternakan, perikanan laut dan kehutanan di wilayah Kabupaten Halmahera Selatan[1].

Beberapa penelitian di FMIPA UNSRAT yang menggunakan Analisis Gerombol, diantaranya: mengelompokkan data wajah yang direduksi dimensi dengan Analisis Komponen Utama [2]. Mengelompokkan mata kuliah yang diajarkan oleh dosen di Prodi Fisika FMIPA UNSRAT berdasarkan mutu pelayanan [3]. Mengelompokkan dosen-dosen di Prodi Matematika berdasarkan presepsi mahasiswa yang mengikuti perkuliahan pada semester genap 2017/2018 [4]. Mengelompokkan SD yang ada di Siau Kabupaten Sitaro berdasarkan indikator mutu sekolah [5]. Mengelompokkan Penggunaan Analisis Two Step Clustering untuk Data Campuran [6].

\section{ANALISIS GEROMBOL (CLUSTER)}

Gerombol dapat diartikan sebagai kelompok dengan demikian pada dasarnya analisis gerombol akan menghasilkan sejumlah gerombol atau kelompok [7].

Metode analisis gerombol membutuhkan suatu ukuran ketakmiripan (jarak) yang didefinisikan untuk setiap pasang objek yang akan dikelompokkan. Ukuran ketakmiripan tersebut sangat tergantung pada sifat variabel (diskrit, kontinu, biner) atau skala pengukuran (nominal, ordinal, interval, rasio) dan pengetahuan bidang yang diteliti. Ukuran jarak dibutuhkan untuk setiap pasang objek yang akan dikelompokkan [8].

Jarak Euclidean merupakan jarak yang umum digunakan dan dapat digunakan apabila semua variabelnya berskala kontinu. Jarak ini harus memenuhi asumsi bahwa variabel-variabel yang diamati tidak berkorelasi dan antar variabel memiliki satuan yang sama. Dalam metode ini, pengukuran jarak dilakukan dengan menghitung akar kuadrat dari penjumlahan kuadrat selisih dari nilai masing-masing variabel. Jarak Euclidean dapat dirumuskan sebagai berikut [9]:

$$
d_{i, j}=\sqrt{\sum_{k=1}^{p}\left(x_{i k}-x_{j k}\right)^{2}}
$$

\subsection{Metode Hirarki Cluster}

Metode ini digunakan untuk menggerombolkan pengamatan secara terstuktur berdasarkan kemiripan sifatnya dan gerombol yang diinginkan belum diketahui banyaknya.

Ada dua cara untuk mendapatkan gerombol dengan metode penggerombolan hirarki yaitu dengan cara penggabungan (aglomerative) dan pemisahan gerombol (devisive). Metode hirarki dengan cara penggabungan didapat dengan menggabungkan pengamatan atau gerombol secara bertahap, sehingga pada akhirnya didapat hanya satu gerombol saja. Sebaliknya cara pemisahan pada metode hirarki dimulai dengan membentuk satu gerombol besar beranggotakan seluruh pengamatan. Gerombol besar tersebut kemudian dipisah menjadi gerombol yang lebih kecil, sampai satu gerombol yang lebih kecil, sampai satu gerombol hanya beranggotakan satu pengamatan saja. Kedua cara dalam metode hirarki ini tidak berbeda dalam pembentukan gerombol yang terjadi tetapi hanya berbeda dalam tahapan pembentukan gerombol saja [7].

\section{METODOLOGI PENELITIAN}

Data yang digunakan dalam penelitian ini adalah data sekunder yaitu data Kabupaten Halmahera Selatan tahun 2018 [1].

Variabel yang di gunakan dalam penelitian ini yaitu $X_{1}$ : Produksi Sayuran (ton/2 tahun), $X_{2}$ : Produksi Buah-buahan (ton/2 tahun), $X_{3}$ : Luasan Pala (ha), $X_{4}$ : Luasan Cengkeh (ha), $X_{5}$ : Jumlah Sapi potong (ekor), $X_{6}$ : Jumlah Kambing (ekor), $X_{7}$ : Jumlah Unggas (ekor), $X_{8}$ : Produksi Perikanan laut (ton/2 tahun), $X_{9}$ : Luasan hutan (ha). Analisis yang digunakan dalam penelitian ini adalah analisis gerombol (cluster) dengan metode single linkage.

Langkah-langkah analisis data sebagai berikut :

1. Menghitung statistik deskripsi variabel-variabel penelitian.

2. Melakukan Standarisasi data.

3. Menghitung matriks jarak dengan jarak euclidean, menggunakan persamaan 1.

4. Membuat Dendogram menggunakan nilai-nilai dalam matriks jarak yang diperoleh dengan metode pautan tunggal (single linkage), menggunakan rumus $d_{(U V)^{W}}=\min \left\{d_{U W}, d_{U V}\right\}$

5. Memotong Dendogram untuk menentukan jumlah kelompok/gerombol, dilakukan pada nilai selisih jarak pengabungan yang terbesar.

\section{HASIL DAN PEMBAHASAN}

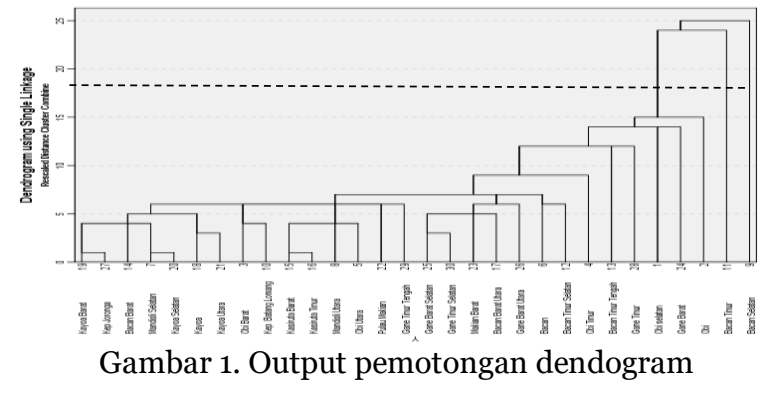

Pada gambar 1 pemotongan dendogram hasil analisis cluster dengan metode single linkage membentuk 3 kelompok, yang di uraikan pada tabel 1 berikut ini : 


\section{Pengelompokkan Kecamatan Berdasarkan Potensi Pertanian di Kabupaten Halmahera Selatan dengan Analisis Gerombol}

d'Cartesian Jurnal Matematika dan Aplikasi, Vol. 9, No. 1, (Maret 2020): 31-34

Tabel 1, pengelompokkan kecamatan

\begin{tabular}{|c|l|}
\hline Kelompok & \multicolumn{1}{|c|}{ Kecamatan } \\
\hline I & $\begin{array}{l}\text { Obi Selatan, Obi, Obi Barat, Obi Timur, } \\
\text { Obi Utara, Bacan, Mandioli Selatan, } \\
\text { Mandioli Utara, Kepulauan Batang } \\
\text { Lomang, Bacan Timur Selatan, Bacan } \\
\text { Timur Tengah, Bacan Barat, Kasiruta } \\
\text { Barat, Kasiruta Timur, Bacan Barat } \\
\text { Utara, Kayoa, Kayoa Barat, Kayoa } \\
\text { Selatan, Kayoa Utara, Pulau Makian, } \\
\text { Makian Barat, Gane Barat, Gane Barat } \\
\text { Selatan, Gane Barat Utara, Kepulauan } \\
\text { Joronga, Gane Timur, Gane Timur } \\
\text { Tengah dan Gane Timur Selatan. }\end{array}$ \\
\hline II & Bacan Selatan \\
\hline III & Bacan Timur \\
\hline
\end{tabular}

Kelompok 1 terdiri dari 28 kecamatan (Tabel 1) pada kelompok ini potensi pertanian masing-masing komoditi di antaranya: X1=Sayuran (9,125 ton) dibawah rata-rata, X2=Buah-buahan (28,146 ton) dibawah ratarata, $X_{3}=$ Luasan Pala (95,32 ha) diatas rata-rata, $\mathrm{X}_{4}=$ Luasan Cengkeh (17,75 ha) dibawah rata-rata, $\mathrm{X}_{5}=$ Sapi Potong (273,143 ekor) dibawah rata-rata, X6=Jumlah Kambing (994,25 ekor) dibawah rata-rata, $\mathrm{X}_{7}=$ Jumlah Unggas (1729,143 ekor) dibawah rata-rata, X8=Perikanan Laut (2331,380 ton) dibawah rata-rata dan X9=Luasan Hutan $(17152,577$ ha) diatas rata-rata. Sehingga dapat di simpulkan bahwa kelompok ini merupakan kelompok yang banyak memiliki hasil produksi pertanian dibawah rata-rata, namun unggul pada $\mathrm{X}_{3}=$ Luasan Pala.

Kelompok 2 yang hanya terdiri dari 1 kecamatan (Tabel 1) pada kelompok ini pertanian masing-masing komoditi di antaranya: X1=Sayuran (39,3 ton) diatas rata-rata, X2=Buah-buahan (45,4 ton) diatas tara-rata, $\mathrm{X}_{3}=$ Luasan Pala (o ha) dibawah rata-rata, $\mathrm{X}_{4}=$ Luasan Cengkeh (25 ha) diatas rata-rata, $\mathrm{X}_{5}=$ Sapi Potong (1438 ekor) diatas rata-rata, X6=Jumlah Kambing (1036 ekor) diatas rata-rata, $\mathrm{X}_{7}=$ Jumlah Unggas (7762 ekor) diatas rata-rata, X8=Perikanan Laut $(12314,27$ ton) diatas ratarata, dan X9=Luasan Hutan (15629,07 ha) dibawah ratarata. Dapat di simpulkan bahwa kelompok ini merupakan kelompok yang banyak memiliki hasil produksi pertanian diatas rata-rata, namun memiliki dua komoditi dibawah rata-rata yaitu $\mathrm{X}_{3}=$ Luasan Pala dan X9=Luasan Hutan. Sehingga kelompok ini hanya terdiri dari satu kecamatan saja karena kecamatan ini merupakan kecamatan yang paling tinggi kedua hasil produksinya di bandingkan kecamatan lain karena kecamatan ini memiliki letak geografis paling luas di pesisir pantai.

Kelompok 3 terdiri dari 1 kecamatan (Tabel 1) pada kelompok ini potensi pertanian masing-masing komoditi di antaranya: X1=Sayuran (52,4 ton) diatas rata-rata, X2=Buah-buahan (57,7 ton) diatas rata-rata, $\mathrm{X}_{3}=$ Luasan Pala (165 ha) diatas rata-rata, $\mathrm{X}_{4}=$ Luasan
Cengkeh (178 ha) diatas rata-rata, $\mathrm{X}_{5}=$ Sapi Potong (430 ekor) diatas rata-rata, X6=Jumlah Kambing (1033 ekor) diatas rata-rata, $\mathrm{X}_{7}=$ Jumlah Unggas (1856 ekor) dibawah rata-rata, X8=Perikanan Laut (7219.47 ton) diatas rata-rata dan $\mathrm{X} 9=$ Luasan Hutan (42658,19 ha) diatas rata-rata. Sehingga dapat di simpulkan bahwa kelompok ini merupakan kelompok dengan hasil produksi pertanian paling tinggi di antara kelompok lain, namun rendah pada $\mathrm{X}_{7}=$ Jumlah Unggas.

\section{KESIMPULAN DAN SARAN Kesimpulan}

Potensi komoditi-komoditi pertanian, perkebunan, peternakan, perikanan laut dan kehutanan di wilayah Kabupaten Halmahera Selatan menghasilkan Kelompok 1 terdiri dari 28 kecamatan yaitu: Obi Selatan, Obi, Obi Barat, Obi Timur, Obi Utara, Bacan, Mandioli Selatan, Mandioli Utara, Kepulauan Batang Lomang, Bacan Timur, Bacan Timur Selatan, Bacan Timur Tengah, Bacan Barat, Kasiruta Barat, Kasiruta Timur, Bacan Barat Utara, Kayoa, Kayoa Barat, Kayoa Selatan, Kayoa Utara, Pulau Makian, Makian Barat, Gane Barat, Gane Barat Selatan, Gane Barat Utara, Kepulauan Joronga, Gane Timur, Gane Timur Tengah dan Gane Timur Selatan. Kelompok 2 hanya terdiri dari kecamatan Bacan Selatan dan Kelompok 3 yang juga hanya terdiri dari kecamatan Bacan Timur.

\section{Saran}

Penulis menyarankan agar Pemerintah Kabupaten Halmahera Selatan lebih memperhatikan kecamatan yang memiliki hasil pertanian yang tinggi.

\section{DAFTAR PUSTAKA}

[1] BPS. 2018. Kabupaten Halmahera Selatan Dalam Angka 2018. BPS Kabupaten Halmahera Selatan, Labuha.

[2] Rindengan, A.J. dan Deiby T.S. 2011. Pengelompokkan Data Wajah Menggunakan Metode Agglomerative Clustering Dengan Analisis Komponen Utama. Jurnal Ilmiah Sains, 11 (2) :178180

[3] Hatidja, D., Lidya I. Momuat dan C. E. Mongi. 2018. Pengelompokkan Mata Kuliah Di Program Studi Fisika FMIPA UNSRAT Berdasarkan Proses Pembelajaran Menggunakan Analisis Cluster. Jurnal Ilmiah Sains, 18(2):107-112

[4] Pamekas, J.A.S., Jantje D. Prang dan D. Hatidja. 2019. Pengelompokan Dosen Berdasarkan Proses Pembelajaran Di Program Studi Matematika FMIPA UNSRAT Pada Semester Genap 2017/2018 Menggunakan Metode Ward. Jurnal Ilmiah Sains, 19 (1) :46-56

[5] Matahari, M., J.S. Kekenusa dan Y.A.R. Langi. 2015. Pengelompokkan Sekolah Dasar Di Siau Berdasarkan Indikator Mutu Sekolah Menggunakan 
Analisis Gerombol. D'cartesian Jurnal Matematika dan Aplikasi, 4(2): 188-195

[6] Mongi, C.E. 2015. Penggunaan Analisis Two Step Clustering untuk Data Campuran. D'cartesian Jurnal Matematika dan Aplikasi, 4(1):9-19

[7] Matijik, A.A., dan Sumertajaya, I.M., 2011. Sidik Peubah Ganda. Kampus IPB Darmaga. Bogor.

[8] Manly and Alberto. 2016. Multivariate Statistical Methods: A Primer, $4^{\text {th }}$ ed. Chapman and Hall. New York.

[9] Johnson, R.A. and D. W. Wichern. 2007. Applied Multivariate Statistical Analysis. 6 $^{\text {th }}$ Ed. Pearson Prentice Hall, New Jersey.

Meilissa Harikadua (meilissaharikadua3o@gmail.com)

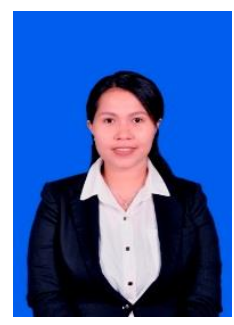

Lahir di ocimaloleo, 30 mei 1994 dan tinggal di manado, Sulawesi utara. Menempuh pendidikan tinggi Jurusan Matematika dan Ilmu Pengetahuan Alam Universitas Sam Ratulangi Manado. Tahun 2019 adalah tahun terakhir ia menempuh studi. Makalah ini merupakan hasil publikasikan. penelitian skripsinya yang di

Djoni Hatidja (dhatidja@yahoo.com)

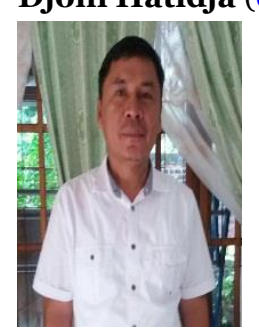

Pada tahun 1994, memperoleh gelar Sarjana di Program Studi Matematika, Institut Pertanian Bogor. Gelar Magister Sains diperoleh dari Institut Pertanian Bogor pada tahun 2000. Menjadi dosen diJurusanMatematika, FMIPA, Universitas Sam Ratulangi Manado sejak tahun 2002 sampai sekarang dengan bidang keahlian yang ditekuni yaitu Statistika.

Charles E. Mongi (Charlesmongi@unsrat.ac.id)

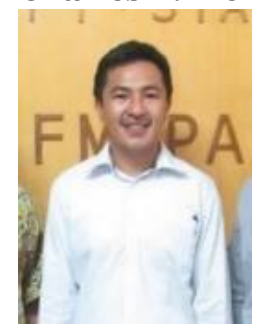

Lahir di Tondano, 04 Januari 1984. Pada tahun 2006 memperoleh gelar Sarjana Matematika di Universitas Sam Ratulangi, Manado. Melanjutkan di Institut Pertanian Bogor tahun 2011 dan mendapatkan gelar Magister Bidang Statistika pada tahun 2014. Menjadi pengajar di Jurusan Matematika, Fakultas Matematika dan Ilmu Pengetahuan Alam Universitas Sam Ratulangi Manado pada tahun 2008. 